\title{
The Navy Core Equipment Support Network System Efficiency Optimization Analysis
}

\author{
Ma Liang \\ Department of Surface Ship Command, Dalian Naval \\ Academy, Dalian, 116018, China; \\ E-mail: maliang2014@tom.com
}

\begin{abstract}
In the core equipment support collaborative degree, on the basis of the core equipment safeguard the synergistic effect of quantitative analysis, core equipment safeguard network performance optimization is put forward based on the navy equipment support network, looking for core equipment support effectiveness biggest path is used to determine the effectiveness of the core equipment support network's biggest. This method can be the core of the collaborative for equipment support effectiveness analysis modeling.
\end{abstract}

Keywords- Synergy Mechanism; The Biggest Effectiveness Pathways; The Core Equipment Support Network

\section{INTRODUCTION}

With information technology as the main body of the high technology group of applications in military field, all kinds of high, refined, sharp weapon and the new combat power service unceasingly, to the army's combat theory, establishment system, operational method, affected the aspects such as equipment safeguard, the operational requirements of the equipment support object, safeguard changes such as the content, the safeguard way, the thinking of equipment support, measures must be adjusted ${ }^{[1]}$. Core support capability, which is enacted by congress in 1984, in the years, the U.S. has been through the core ability theory to ensure that the security forces to complete the mission critical ability, to deal with the use of local security forces in the security business, moderate protection system safeguard ability has a very important role. The war in Iraq in 2003, its core equipment support theory to test ${ }^{[2]}$. Equipment and combat is complementary to each other, what wars between what kind of weapons and equipment, you need to the corresponding guarantee ability, according to the needs of current carries out our mission and our core equipment support ability is an important link in improving fighting capacity generation, how to scientifically plan the core equipment safeguard for the construction of the network, to form the overall network effect, improve the efficiency of security at present is an urgent need to solve the problem.

\section{THE BASIC FACTOR ANALYSIS TO CONSTRUCT THE CORE EQUIPMENT SUPPORT NETWORK}

\section{A. The Core Equipment Support Units SCU}

In the construction of core ability of equipment support, the core equipment safeguard network information platform endowed with new connotation and denotation. Of the integrated system is the key to the construction of the core equipment support network,

\author{
Cui Chao \\ Department of Surface Ship Command, Dalian Naval \\ Academy, Dalian, 116018, China; \\ E-mail: mailbox1314@126.com
}

under the thought of integrated, information equipment support force will be composed of innumerable small equipment safeguard system, the small equipment support system through mutual connection, formed a huge system of "system", which is the core equipment support the construction of network, according to the theory of complex network can take the equipment support units, namely small system called adaptive equipment safeguard the main body, hereinafter referred to as the core unit of the equipment support network SCU (systematical combat unit) ${ }^{[3]}$. SCU system combats units (systematical combat unit) of English abbreviations. Each SCU has access to information, processing information, information, and the ability to response information. In equipment support networks, SCU can interact and protecting environment as well as other SCU. In the process of interaction, SCU constantly "learning" and "experience", and according to the study of knowledge and experience to change their own behavior structure and operating mode. Can evolve and evolution of the equipment support system, including the new style, new level and new subject formation, differentiation, polymerization to form a bigger security system.

\section{B. The Core Equipment Safeguard Mechanism}

Core equipment safeguard mechanism is the SCU interaction rules and ways, the core of an effective and reasonable equipment safeguard mechanism can make internal "orderly" together generate self-organizing network system ${ }^{[4]}$. Systems in a self-organizing system, the result does not require an external command intervention, it can be based on the collaborative mechanism, and different conditions gradually evolved into a collaborative organization architecture, and show the different functions. At this point, the external command by the state of the environment control system parameters changes to the critical value, create necessary conditions for the evolution into the new structure. A system if there are several order parameters, will exist interdependence, competition between two states, and each order parameter can decision system of a micro structure and the corresponding macro state.

\section{CORE EQUIPMENT SUPPORT NETWORK ABILITY PROMOTION MECHANISM ANALYSIS}

In the core equipment support network, to form the biggest effectiveness must meet the following conditions:

Condition 1: core equipment safeguard in the network due to multiple security of SCU, its protection ability will be improved. 
Condition 2: the core ability of the equipment support network emergence is greater than the sum of individual SCU support capability.

Set guarantee network performance $U$ as the core equipment, core equipment support network in the $i$ in SCU is $V_{i}=\left\{v_{i 1}, v_{i 2} \ldots, v_{i l}\right\}$ for which the said core equipment support network of different SCU; Said the $i$ order parameter component core equipment safeguard network subsystem, without taking the core equipment safeguard mechanism of order parameter for the $\operatorname{SCU} \quad V_{i}^{\prime}=\left\{v_{i 1}^{\prime}, v_{i 2}^{\prime} \ldots, v_{i l}^{\prime}\right\}(i=1,2, \ldots n ; l=1,2, \ldots m)$, because each SCU in separate carries out equipment support tasks, influenced by the environment and the limitation of their own command security instructions, the Angle of guarantee ability, there must be between each SCU two reaction ability is not in the same direction, will produce an internal friction. Under the condition of system security, through the guarantee mechanism of synergistic effect, make each SCU is parallel to the trend and direction ${ }^{[5]}$, so:

$$
\begin{aligned}
& \max \sum_{i=1}^{n} V_{i}^{\prime}=\max \left(V_{1}^{\prime}+V_{2}^{\prime}+\ldots+V_{i}^{\prime}\right) \\
& =\left(V_{1}^{\prime}+V_{2}^{\prime}+\ldots+V_{n}^{\prime}\right)=U
\end{aligned}
$$

The core equipment safeguard network emerges stronger than the sum of individual SCU security forces. That is:

$$
U>\sum_{i=1}^{n} V_{i}^{\prime}
$$

Because each SCU in command mode, training mode, differences exist, so the core equipment support network of SCU inevitably exist in the process of collaborative conflict and friction. In the case of a "resistance", the core equipment safeguard network need to overcome the "resistance", system to produce internal friction. "Resistance" between SCU alignments, the structure of the mechanism with the size of the reasonable gradient, protection function measurement equipment and so on, the direction and core equipment support network to achieve the goal in the opposite direction.

$$
f=-\gamma \frac{d U}{d t}
$$

Core equipment safeguard network under the action of friction, safeguarding capacity will gradually reduce, in order to overcome the friction effect, through the synergy mechanism, coordinated, the mutual fusion and security unit between each SCU reasonable distribution, core equipment safeguard network security ability gradually improve ${ }^{[6]}$. Therefore core equipment safeguards network collaborative force and guarantee ability of ascension in the same direction. The ability to guarantee the convergence of safeguard power is the consistency, the better, the greater, and the force together.

\section{MOST EFFICIENCY PATH AT THE CORE OF THE EQUIPMENT SUPPORT NETWORK BUILDING}

\section{A. The Core Equipment Support Network of Wide-area Protection Function Matrix}

Core equipment safeguard network security procedure can be broken down into several security range, due to the coordination degree between SCU different range on each security protection performance is also different. First determine individual SCU security solutions on the basis of efficiency $E J_{i}(j)$ and coordinated degree $X T_{i}(j)$, and then determine the security of the SCU security effectiveness $E_{i}(j)$.

$$
E_{i}(j)=E J_{i}(j) \cdot\left(1+X T_{i}(j)\right)
$$

Type, $E J_{i}(j)$ is the SCU protection programs $A_{i}$ in the region $B_{j}$ of basic guarantee efficiency. $X T_{i}(j)$ Said in the security area $B_{j}$, ensure the way of coordination $A_{i}$ with other kinds of safeguard way n-1 degrees. $X T_{i}(j)$ is defined with the following formula:

$$
\left.X T_{i}(j)\right|_{A_{i}} ^{B_{j}=} \begin{array}{llll}
A_{1} A_{2} & \ldots & A_{n} \\
X T_{i 1} & X T_{i 2} & \ldots & X T_{i n}
\end{array}
$$

With each security in the area $B_{j}$ of the protection scheme may adopt collaborative probability and to describe the value of the synergy degree, namely:

$$
X T_{i}(j)=\sum_{t=1}^{n} p_{t} \cdot\left\{X T_{i t}(j)\right\}
$$

Construct two sets, a set of is the guarantee scheme $\left\{A_{i}\right\}, i=1,2, \ldots, n$ and the other one is the region set $\left\{B_{i}\right\} j=1,2, \ldots, m$, used to say. So can generate wide-area protection efficiency matrix, namely:

$$
E=\left[\begin{array}{cccc}
E_{11} & E_{12} & \cdots & E_{1 m} \\
E_{21} & \cdots & \cdots & \cdots \\
\cdots & \cdots & E_{i j} & \cdots \\
E_{n 1} & \cdots & \cdots & E_{n m}
\end{array}\right]
$$

\section{B. The Biggest Efficiency of Path Construction Method}

A connected graph $G=(V, A)$, and on behalf of the vertex set $V$ under the security mission requirements of the various optional SCU, vertex set $V$ can be divided into multiple stages, with vertex $i \in V$ as the basic performance, each vertex $\left(\overrightarrow{x_{i j}}, \overrightarrow{x_{j i}}\right) \in A \quad$ can be associated with different stages of each vertex, namely there is contact information, on both sides can work together. With said the core of the vertex and equipment 
support collaborative degree $j \in V, \overrightarrow{x_{i j}}, \overrightarrow{x_{j i}} \geq 0$. If belong to two different stages, and yes the previous stage, the existence $\overrightarrow{x_{i j}}$, otherwise there is no $\overrightarrow{x_{i j}}$.

A core equipment support effectiveness of feasible path if contains can increase the total guarantee efficiency and effectiveness of vertices, the efficiency of the feasible pathway is the core equipment support effectiveness augmented road, the vertex as the core equipment support effectiveness is feasible. Core equipment support effectiveness can be called feasible vertex is conditional on the vertices joined with a positive contribution to the overall efficiency of the network value, as shown in figure 1.

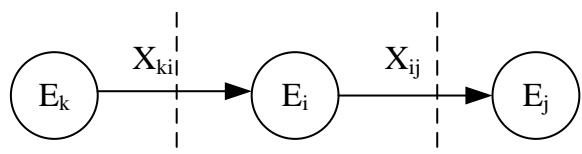

Figure 1. Core Equipment Safeguard Network Feasible Function diagram

In figure 1 , the vertex $i$ as the core equipment support effectiveness is feasible, and its basic performance is $E_{i}$, its effect on the vertices $j$ is $\overrightarrow{x_{i j}}, \mathrm{j}=1$, 2,..,M. Similarly, the influence of the vertex will $\mathrm{k}$ is $\overrightarrow{x_{k i}}$, $\mathrm{k}=1,2, \ldots, \mathrm{M}$. After joining the vertices $i$, the core equipment safeguard network efficiency contribution said with the following formula:

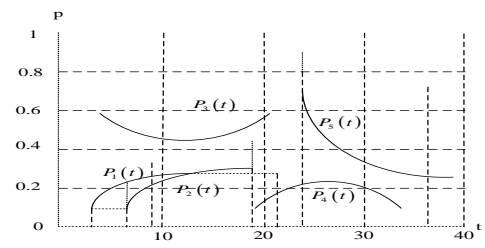

If $\Delta E_{i}>0$, vertex $i$ can be incorporated into the core within the vertex set of efficiency of the equipment support network available.

Through the type (6), the core equipment support network efficiency increment contains three items:

The first is the basic core of should vertex equipment support effectiveness, its contribution to the total effectiveness is positive, and the bigger the basic core equipment support effectiveness, the greater the value of its contribution. The second for other vertices to the vertex $i$ and the effect of using said $\overrightarrow{x_{k i}}, \overrightarrow{x_{k i}}$ is positive number is greater than zero. The third for the influence of the vertex to other vertices, used to indicate its size. The value is $\overrightarrow{x_{i j}}$, the greater the said the vertex to other vertex basic core equipment support effectiveness play has a serious impact, a negative contribution. The smaller this value, said the vertices joined to other vertices core function of the equipment support effectiveness influence is small. In core equipment safeguard in the network, the vertex, and the more the greater the total core equipment support effectiveness.
In the directed graph $G$ vertex $y$ take a subset of each vertex of the new structure a pathway $D$, satisfy the following conditions pathway known as the core equipment support effectiveness is feasible, and subset called efficiency feasible subsets.

Condition 1: periodic

Composed of a subset of new core equipment safeguard network efficiency feasible path $D$, then the pathway of initial vertex inevitable in phase 1 of the concentration, and must end in the final stage of the vertex set.

Condition 2: irreversibility

In form the core of the equipment support network efficiency feasible pathway side concentrated cannot exist on the side. If, $i j$ respectively in two different stages, and is located in the previous stage.

Under the condition of the above, the core equipment can be traced to guarantee the maximum efficiency path of a feasible pathway of efficiency $Y \in D$, makes the biggest $E(y)=\sum_{i=1}^{l} E_{i} X T_{i}$. Type, $1 \leq M, M$ and as the core equipment support the number of all the nodes in a network. $X T_{i}$ said considering the vertex $i$ basic performance and the influence of the vertex with other influence each other, see type (8).

Core equipment support effectiveness feasible pathway is channel increases on the starting point and the limitation of irreversible, and is located in the edge sets. The optimization goal to maximize efficiency is feasible. In order to get maximum effectiveness of feasible path, on the need to build the core equipment support network for further design and planning, core equipment support network more in line with the requirements of SCU collaborative decision-making.

As the core of the SCU equipment support effectiveness $E_{i}$ is made up of multiple child efficiency index, which is formed when the problem is converted into multiple core index of equipment support effectiveness $\left(E_{i}^{1}, E_{i}^{2}, \ldots, E_{i}^{n}\right)$. Set the vertex $i$ of the basic performance $E_{i}=\left(E_{i}^{1}, E_{i}^{2}, \ldots, E_{i}^{n}\right)$, namely the basic performance indicators. Each vertex efficiency increment formulas (8) to solve component is still available. In order to determine the effectiveness of vertex is feasible vertices, introduced a concept of optimal efficiency, assume that the vertices of maximum effectiveness as follows.

$$
E_{\max }=\left(E_{\max }^{1}, E_{\max }^{2}, \ldots, E_{\max }^{n}\right)
$$

Minimum efficiency value is:

$$
E_{\text {min }}=\left(E_{\min }^{1}, E_{\min }^{2}, \ldots, E_{\min }^{n}\right)
$$




$$
u_{i}^{j}=\left\{\begin{array}{c}
\frac{\Delta E_{i}^{j}-E_{\min }^{j}}{E_{\max }^{j}-E_{\min }^{j}} \\
-\frac{\Delta E_{i}^{j}-E_{\min }^{j}}{E_{\max }^{j}-E_{\min }^{j}} \\
u_{i}=\sum_{j=1}^{n} w^{j} u_{i}^{j}
\end{array}\right.
$$

\section{CONCLUSION}

Core equipment safeguard network between each subsystem, due to the existence and safeguard equipment safeguard system, the safeguard way difference, inevitably produce system internal friction. The direction of the friction force is always with the core ability of the equipment support network in the opposite direction. Security mechanism can reduce the network internal friction increases synergistic effect to promote the core equipment support network has a larger network effects.

\section{REFERENCES}

[1] WANG Hong-jun, CHI Zhong-xian.Shipboard hard and soft weapon anti-missile decision-makingoptimization based on collaboration[J], Control and Decision, 2007, 22 (3) : 299303

[2] LIU Wei dong, JIANG Qing shan, LI Yong.Fire distribution of the network centric ship-to-air missile based on earlier damage[J],Ship Science And Technology, 2011,33 (2) : :98-101

[3] CHEN Guo sheng, JIA $\mathrm{Zi}$ ying.Research on coordinated air defense firepower distribution model for warships[J], Command ControI\& Simulation, 2011,33 (12) : 13-15

[4] XU Z S. Multiple-attribute group decision making with different formats of preference information on attributes [J]. IEEE Trans on
System, Man, and Cybernetics-Part B: Cybernetics, 2007, 37 (6) : 1500-1511.

[5] A.Hadi-Vencheh, M.Allame. On the relation between a fuzzy number and its centroid [J].Comput. Math. Appl, 2010, 59: 3578-3582

[6] Lee Z J, Su S F, Lee C Y. Efficiently solving general weapontarget assignment problem by genetic algorithms with greedy eugenics [J].IEEE Transactions on Systems. Man and CyberneticsPartB, 2003, 33 (1): 113-121.

[7] Abdollah, Mahdi. Seclusion-Factor Method to solve fuzzy-multiple criteria decision-making problems [J].IEEE Trans on Fuzzy Systems, 2011, 19 (2): 201-209.

[8] Beynon M J, Bruce Curry, Peter Morgan. The Dempster-Shafer theory of evidence: An alternative approach to multi-criteria decision modeling [J]. Omega, 2000, 28(1):37-50.

[9] Beynon M J. DS/AHP method: A mathematical analysis,including an understanding of uncertainty[J]. European $\mathrm{J}$ of Operational Research, 2002, 140(1): 148-164.

[10] COP 21 TD : Common Operational Picture 21st Century Technology Demonstra -tion[R]. Defence R\&D Canada Valcartier, www.valcartier.drdc-rddc.gc.ca.

[11] Dr.David Baar, Garth Shoemaker. Pliable Display Technology for the Common Operational Picture[R]. IDELIX Software Inc

[12] Denis Gouin, Alexandre Bergeron GuyardNovel. Concepts for the COP of the Future [J]. RTO-MP-IST-043, $2005: 1-12$.

[13] Paul W. Richmond, Curtis L.Blais, Joyce A. Nagle. Standards for the Mobility Common Operational Picture (M-COP : Elements of Ground Vehicle Maneuver[C]. Engineer Research and Development Center, 2007.

[14] Hedvig Sidenbladh , Pontus Svenson , Johan Schubert. Comparing Future Situation Pictures[C]. International Conference on Information Fusion, 2005.

[15] Common Operational Picture Staying on top of dynamic situations in an ocean of information[R]. www.xwave.corn

[16] Kusiak A, szczerbicki, E.Vojosevic R. Intelligent design synthesis:an object oriented approach[J]. International journal of production Research , 1991，29(7) : 1291-1308. 